\title{
Family Medicine
}

\section{Disciplinary attitudes and cigarette smoking: a comparison of two schools}

\author{
ALAN PORTER
}

\begin{abstract}
Two British boarding schools for boys with different disciplinary policies in respect of cigarette smoking were identified. Questionnaires were sent to the young "old boys" of each school to determine their present smoking habit and most were returned (school A $81 \%$, school B $83 \%$ ). Significantly more responders smoked who had been to the less strict school (school A 39\%, school B $30 \%, \mathbf{p}<0.05)$. These figures probably underestimate the smoking prevalence in the two complete groups. The results suggest that measures that reduce the exposure of an uncommitted adolescent to peer group smoking decrease the chances of tobacco dependence in adulthood.
\end{abstract}

\section{Introduction}

There is a lack of understanding about why young people start to smoke.' This study compares the outcome of different disciplinary policies in two British boarding schools (public schools) and tests the null hypothesis that a strict disciplinary policy during adolescence does not lessen the chance of a cigarette-smoking outcome in the young adult.

\section{Method}

Two public schools for boys were identified with different disciplinary policies. With the consent of the headmasters questionnaires were sent to the young "old boys" to determine their present smoking habit and other details.

School A, a Roman Catholic foundation, is slightly larger than school B, a Church of England foundation. Boys go to the schools aged 13 and normally leave aged 17 or 18 . They pass two-thirds of each year at school away from the influence of their home. School A allowed senior boys to smoke in their rooms with their parents' written permission "as a concession to reality" but was "firmly committed against the practice among junior boys." School B had a strict antismoking policy applying to all boys. Punishments included "extra work and runs at inconvenient times" and sometimes corporal punishment for younger boys. In each school disciplinary attitudes varied from house to house and during their time at school each boy was exposed at least once to an antismoking film and lecture. Another school with a policy similar to that of school A was not identified and this restricted the study to two schools.

Camberley, Surrey

A $M W$ PORTER, MD, MRCGP, general practitioner
A sample of 150 "old boys" from each school would give an $80 \%$ chance of detecting a $15 \%$ difference in smoking rates significant at the $5 \%$ level if the proportion of smokers in one of the schools was $25 \%$. To allow the examination of the smoking behaviour of subgroups the number was doubled to 340 from school A and 289 from school B. These numbers represent three years' output from each school. The lapsed time since leaving school and receiving a questionnaire therefore varied from 0.5 to 2.5 years.

Questionnaires, which were kept brief to encourage compliance, were sent by post with a stamped-addressed envelope and an explanatory letter. Those who had not replied within two months were sent a reminder. The seven questions established the year that the subject left school, his present cigarette-smoking habit, the cigarette-smoking habit of parents and older siblings while he was at school, and his father's occupation. A space was left headed "Comments, if any." Smoking was defined as at least one cigarette a day for six days a week. No questions were asked relating to the subject's smoking habit while at school. Subsequent analysis included a comparison of the proportion who smoked from each school in each category of parental and sibling smoking status using the chi square statistic. In addition multiple regression was performed to confirm the independent contribution of each of the factors found to influence the subject's smoking habit.

Indirect information was sought about the smoking habits of the one in five subjects who did not reply. The distribution of the lapsed time in days between posting the questionnaires and their return was determined. The distribution, which was positively skewed, could be divided into two halves by the median, the first half representing the prompt responders and the second half the intermediate responders. The ratio of smokers to non-smokers for each school was calculated for each of the following three groups (response waves): the first median of the first mailing ("prompt"); the second median of the first mailing ("intermediate"); and the whole of the second mailing ("late"). The three ratios formed points on an ordinal scale of increasing dilatoriness and by extrapolation an insight may be gained into the proportion of smokers in the non-responding groups.

\section{Results}

These are summarised in the table. The response rate after two mailings was 277 out of $340(81 \%)$ for school A and 241 out of $289(83 \%)$ for school B. More subjects from school A $(39 \%)$ admitted smoking cigarettes than from school B (30\%). The difference is significant (chi square $=4.3$ with Yates's correction, $\mathrm{p}<0.05$ ). The proportions of smokers were similar whichever year the subjects had left school (table). The mean number of cigarettes smoked per day among the smokers was 
Proportion of respondents smoking related to different variables

\begin{tabular}{|c|c|c|c|c|}
\hline & \multicolumn{2}{|c|}{ School A } & \multicolumn{2}{|c|}{ School B } \\
\hline & $\begin{array}{l}\text { No (\%) who } \\
\text { admitted } \\
\text { smoking }\end{array}$ & $\begin{array}{c}\text { Total No } \\
\text { of } \\
\text { respondents }\end{array}$ & $\begin{array}{l}\text { No (\%) who } \\
\text { admitted } \\
\text { smoking }\end{array}$ & $\begin{array}{c}\text { Total No } \\
\text { of } \\
\text { respondents }\end{array}$ \\
\hline Overall & $108(39)^{*}$ & 277 & $72(30) *$ & 241 \\
\hline $\begin{array}{l}\text { Parental smoking: } \\
\text { At least one smoked } \\
\text { Non-smokers } \\
\text { Question not answered } \\
\text { Older sibling: }\end{array}$ & $\begin{array}{l}45(39) \\
62(38)\end{array}$ & $\begin{array}{r}114 \\
162 \\
1\end{array}$ & $\begin{array}{l}31(33) \\
41(28)\end{array}$ & $\begin{array}{r}94 \\
147 \\
0\end{array}$ \\
\hline $\begin{array}{l}\text { No older sibling } \\
\text { Smoker } \\
\text { Non-smoker } \\
\text { Question not answered: } \\
\text { Lapsed time since leaving } \\
\text { school in years: }\end{array}$ & $\begin{array}{l}38(43) \dagger \\
44(45) \\
24(28)\end{array}$ & $\begin{array}{r}88 \\
98 \\
87 \\
4\end{array}$ & $\begin{array}{l}19(24) \dagger \\
35(48) \\
18(20)\end{array}$ & $\begin{array}{r}80 \\
73 \\
88 \\
0\end{array}$ \\
\hline $\begin{array}{l}0.5 \\
1.5 \\
2.5 \\
\text { Question not answered } \\
\text { Return of questionnaires: }\end{array}$ & $\begin{array}{l}31(39) \\
43(39) \\
34(39)\end{array}$ & $\begin{array}{r}79 \\
111 \\
87 \\
0\end{array}$ & $\begin{array}{l}19(29) \\
30(32) \\
22(27)\end{array}$ & $\begin{array}{r}65 \\
94 \\
81 \\
1\end{array}$ \\
\hline $\begin{array}{l}\text { Prompt } \\
\text { Intermediate } \\
\text { Late } \\
\text { Uncertain }\end{array}$ & $\begin{array}{l}38(36) \\
45(40) \\
24(43)\end{array}$ & $\begin{array}{r}107 \\
112 \\
56 \\
2\end{array}$ & $\begin{array}{l}27(28) \\
27(29) \\
18(35)\end{array}$ & $\begin{array}{r}97 \\
92 \\
52 \\
0\end{array}$ \\
\hline
\end{tabular}

$* p<0.05 .+p<0.02$

similar in each school (school A mean 14.5, SD 11.0; school B mean $13 \cdot 6$, SD 7.2).

Public schools draw their pupils almost exclusively from social group I, and the range of paternal occupations for each school was shown to be similar. A similar proportion of "one parent at least" had smoked during the subjects' schooldays (school A 41\%, school B 39\%). Parental smoking had little influence on that of the subjects (table). One housemaster only from school A and none from school B smoked cigarettes.

Rather more of the older siblings of subjects from school A smoked than those of subjects from school B (53\% and $45 \%)$, but the difference was not significant. Multiple regression analysis using percentage of smokers as the dependent variable showed that both the school attended and having an older sibling who smoked were significant predictors $(p<0.05$ and $p<0.001$ respectively) of smoking by the subjects of the survey, while having a parent who smoked was not.

Fifty-five per cent of the respondents from school A and $59 \%$ from school B added a comment. Only six (1\%) were facetious or rude. The remainder were responsible and often percipient.

A trend for an increase in the proportion of cigarette smokers for each school in each of the response waves was shown (table). This suggests that the proportion of smokers among the responders (school A 39\%, school B 30\%) underestimates the proportion for the complete group in each school but does not suggest that the comparison between the schools was biased.

\section{Discussion}

The difference between the schools in the proportion of young "old boys" who smoked was statistically significant and was consistent in each of the three years of school-leavers studied, in each of the response waves, and in each category of parental and older sibling smoking status. The one exception was that in school B the existence of an older sibling who smoked seemed to overrule the effect of the school. These findings suggest that the null hypothesis should probably be rejected. The effect of the school seems to have been confined to smoking or not smoking; the number of cigarettes consumed per day by the smokers was similar in each school. The possibility exists that one or more unidentified factors contributed to the difference. The two groups, however, seem to have been similar in everything except their smoking habit and religion. They were comparable for social class, paternal occupation, parental and older sibling smoking habits, the abstention from smoking of their housemasters, the proportion of subjects who returned forms, the proportion who added comments, and the type of comment made.
An American study reports a higher smoking rate in a Catholic school compared with others. ${ }^{2}$ In this study a similar proportion of parents smoked and this is evidence against the religious difference being important. The third report of the Royal College of Physicians ${ }^{3}$ and many other references testify to the concordance between the smoking habit of a subject and that of parents and older siblings. In this study this association was confirmed for siblings but not for parents. The lack of parental influence may be due to the length of time the subjects spent away from home during their schooldays. The association with the habit of an older sibling cannot be assumed to be causal for half the older siblings were male and they would have often attended the same school as the subject and thus the variable is not independent. Subjects from school A without an older sibling were much more likely to smoke than similar subjects from school B. The explanation for this is obscure, but it is possible that in school $A$ the older boys tended to fulfil the role of a sibling substitute and exerted an adverse influence in respect of cigarette smoking.

It is difficult to determine how the prevalence of smoking in the subjects compares with other youths in the United Kingdom. Data are collected by the Office of Population Censuses and Surveys, ${ }^{4}$ but only 53 men were interviewed aged 16 to 24 in professional group 1 in the last census in 1980. In 1980 some $21 \%$ of professional men in the United Kingdom of all age groups smoked cigarettes and $32 \%$ of youths aged 16 to 19 of all social classes. Thus the subjects of this study have a higher smoking prevalence than might be expected. Considerable difficulties of breaking the habit of tobacco dependence lie ahead if they are to adjust to the overall prevalence of their social class. The constant proportion of smokers for each of the three leaving years may conceal some change in smoking status in each direction. It does not, however, suggest a flight from smoking within three years of leaving school.

The most probable explanation for the difference in smoking prevalence between the two groups is that a vigorously enforced antismoking policy in a closed schoolboy community reduces the exposure of an uncommitted adolescent to peer group smoking and decreases the chance of eventual tobacco dependence.

I thank the headmasters for permission to approach their "old boys"; the "old boys" for their co-operation; and Dr R Heller, department of community medicine, St Thomas's Hospital, for advice. The study was financed by a grant from the research foundation of the Royal College of General Practitioners.

Reprints will not be available.

\section{References}

1 Banks MH, Bewley BR, Bland JM, Dean JR, Pollard V. Long-term study of smoking by secondary schoolchildren. Arch Dis Child 1978;53:12-9.

${ }^{2}$ Horn D, Courts FA, Taylor RM, Solomon ES, Solomon MA. Cigarette smoking among high school students. Am f Public Health 1959;49: 1497-1511.

${ }^{3}$ Royal College of Physicians of London. Smoking or health. Third report. London: Pitman Medical, 1977.

4 Office of Population Censuses and Surveys. Cigarette smoking: 1972 to 1980. London: OPCS, 1981.

(Accepted 5 September 1982)

What effect does long term administration of aspirin have on the kidney?

There is no evidence that long term ingestion of aspirin alone affects the human kidney. The effect on experimental animals varies with the species considered and any associated drugs. Other analgesics have been suggested as causing papillary necrosis in man, but only as an exceptional event.-D B WEBB, lecturer in medicine, Cardiff.

Morales A, Steyn J. Papillary necrosis following phenylbutazone ingestion. Arch Surg 1971;103:420-1. 